\title{
Palmitate and oleate exert differential effects on insulin signalling and glucose uptake in human skeletal muscle cells
}

\author{
Selina Mäkinen ${ }^{1,2, *}$, Yen H Nguyen ${ }^{1,2}$ *, Paulina Skrobuk ${ }^{1,2}$ and Heikki A Koistinen ${ }^{1,2}$ \\ ${ }^{1}$ Minerva Foundation Institute for Medical Research, Helsinki, Finland \\ ${ }^{2}$ University of Helsinki, Department of Medicine, and Abdominal Center, Endocrinology, Helsinki \\ University Central Hospital, Helsinki, Finland \\ *(S Mäkinen and Y H Nguyen contributed equally to this work)
}

Correspondence

should be addressed

to $\mathrm{H}$ A Koistinen

Email

heikki.koistinen@helsinki.fi

\begin{abstract}
Saturated fatty acids are implicated in the development of insulin resistance, whereas unsaturated fatty acids may have a protective effect on metabolism. We tested in primary human myotubes if insulin resistance induced by saturated fatty acid palmitate can be ameliorated by concomitant exposure to unsaturated fatty acid oleate. Primary human myotubes were pretreated with palmitate, oleate or their combination for $12 \mathrm{~h}$. Glucose uptake was determined by intracellular accumulation of $\left[{ }^{3} \mathrm{H}\right]$-2-deoxy-D-glucose, insulin signalling and activation of endoplasmic reticulum (ER) stress by Western blotting, and mitochondrial reactive oxygen species (ROS) production by fluorescent dye MitoSOX. Exposure of primary human myotubes to palmitate impaired insulin-stimulated Akt-Ser ${ }^{473}$, AS160 and GSK-3 $\beta$ phosphorylation, induced ER stress signalling target PERK and stress kinase JNK 54 kDa isoform. These effects were virtually abolished by concomitant exposure of palmitate-treated myotubes to oleate. However, an exposure to palmitate, oleate or their combination reduced insulin-stimulated glucose uptake. This was associated with increased mitochondrial ROS production in palmitate-treated myotubes co-incubated with oleate, and was alleviated by antioxidants MitoTempo and Tempol. Thus, metabolic and intracellular signalling events diverge in myotubes treated with palmitate and oleate. Exposure of human myotubes to excess fatty acids increases ROS production and induces insulin resistance.
\end{abstract}

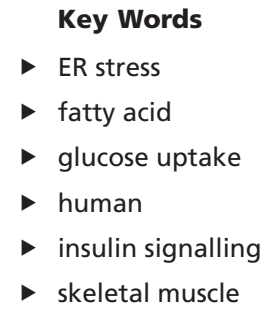

Endocrine Connections (2017) 6, 331-339

\section{Introduction}

Excess dietary fat and sedentary lifestyle predispose to insulin resistance and type 2 diabetes. As skeletal muscle accounts for $80 \%$ of glucose disposal under insulinstimulated conditions $(1,2)$, it is an important target tissue to study insulin action. Increased fat availability and reduced fatty acid oxidation in skeletal muscle from obese type 2 diabetic people favour ectopic storage of fat in muscle (3). This has been suggested to induce insulin resistance via generation of active fatty acid-derived metabolites, such as diacylglycerol (DAG), long-chain fatty acyl-CoA:s and ceramides. These metabolites can interfere with insulin signal transduction (4). Mitochondrial fat overload and incomplete oxidation of fatty acids have also emerged as players in pathogenesis 
of muscle insulin resistance (5). However, the molecular mechanisms whereby excess fatty acids lead to reduced insulin action are still incompletely understood.

Increased intake of saturated fatty acids leads to insulin resistance $(6,7)$. Conversely, diet high in monounsaturated fatty acids has been associated with improved insulin sensitivity $(7,8)$. Mediterranean diet is rich in monounsaturated fatty acids and low in saturated fats, and it has been shown to protect against major cardiovascular events (9) and T2D (10). However, the beneficial effect of monounsaturated fat on insulin sensitivity has been lost if the overall fat intake has been high (7). Taken together, these data indicate that both quality and quantity of dietary fat play a role in regulating insulin sensitivity.

Recent cell-based studies have provided evidence that co-incubation with monounsaturated fatty acid oleate protects against saturated fatty acid palmitate-induced insulin resistance $(11,12,13)$. Since data on human skeletal muscle are limited, the current study was initiated to explore whether there is a similar interaction with different fatty acids in primary human muscle cells. We tested if adding oleate to palmitate would protect muscle cells from palmitate-induced insulin resistance.

\section{Materials and methods}

\section{Participants}

The study was reviewed and approved by the Ethical Committee of Department of Medicine, Helsinki University Central Hospital, and written informed consent was obtained from all subjects before participation. The reported investigations have been carried out in accordance

Table 1 Clinical characteristics of the healthy male volunteers studied.

\begin{tabular}{lc}
\hline$N$ & 8 \\
Age (years) & $55 \pm 3$ \\
BMI $\left(\mathrm{kg} / \mathrm{m}^{2}\right)$ & $23.2 \pm 0.7$ \\
Waist $(\mathrm{cm})$ & $90 \pm 4$ \\
Hip $(\mathrm{cm})$ & $96 \pm 1$ \\
Waist-to-hip ratio & $0.94 \pm 0.03$ \\
Systolic blood pressure $(\mathrm{mmHg})$ & $141 \pm 6$ \\
Diastolic blood pressure $(\mathrm{mmHg})$ & $87 \pm 4$ \\
Fasting plasma glucose $(\mathrm{mmol} / \mathrm{L})$ & $5.5 \pm 0.2$ \\
HbA1c (\% (mmol/mol)) & $5.4 \pm 0.1(36 \pm 1)$ \\
Fasting cholesterol (mmol/L) & $5.4 \pm 0.4$ \\
Fasting HDL cholesterol (mmol/L) & $1.5 \pm 0.2$ \\
Fasting LDL cholesterol (mmol/L) & $3.3 \pm 0.5$ \\
Fasting triacylglycerols (mmol/L) & $1.4 \pm 0.2$ \\
\hline
\end{tabular}

Data are presented as mean \pm S.E.M. with the principles of the Declaration of Helsinki as revised in 2008. We studied 8 healthy nonsmoking men (Table 1). None of the subjects was taking any medications, and all had normal glucose tolerance in standard ( 75 g glucose) oral glucose tolerance test (WHO criteria). Subjects were studied after an overnight fast and were instructed to abstain from physical exercise for at least $72 \mathrm{~h}$ before the studies.

\section{Muscle cell preparation}

Satellite cells were isolated, and primary human muscle cell cultures were established as described (14). In brief, after obtaining a biopsy from vastus lateralis muscle under local anaesthesia $(10 \mathrm{mg} / \mathrm{mL}$ lidocain hydrochloride), the muscle tissue was dissected into small pieces, followed by trypsinization in a shaking water bath at $+37^{\circ} \mathrm{C}$ for $1 \mathrm{~h}$. Satellite cells were isolated and maintained in DMEM-F12 culture medium (Gibco/Thermo Fisher Scientific) containing 20\% fetal bovine serum (FBS), 1\% penicillin, 1\% streptomycin and 1\% fungizone. Primary myoblasts were separated from non-myogenic cells with CD56-coupled magnetic beads (Miltenyi Biotec, Gologne, Germany). To obtain myotubes, myoblasts at $80 \%$ confluence were switched to differentiation medium containing $2 \%$ FBS for 5-7 days. The cells were serum starved for $2 \mathrm{~h}$ before any treatment in low-glucose DMEM supplemented with $0.5 \%$ fatty acid-free BSA and $4 \mathrm{mM}$ L-glutamine. All chemical treatments were prepared in starvation medium supplemented with $2 \mathrm{mM}$ L-carnitine (5).

\section{Pre-treatment with BSA-conjugated fatty acids}

Fatty acids conjugated with BSA and vehicle controlBSA-NaOH were prepared before each experiment based on previously reported procedure (15). Primary human myotubes were pretreated with $0.4 \mathrm{mM}$ palmitate or $0.2 \mathrm{mM}$ oleate, or with combination of $0.4 \mathrm{mM}$ palmitate and $0.2 \mathrm{mM}$ oleate, at $37^{\circ} \mathrm{C}$ for $12 \mathrm{~h}$. In some experiments, myotubes were pretreated with antioxidants MitoTempo $(50 \mu \mathrm{M})$ or Tempol $(0.5 \mathrm{mM})$ for $12 \mathrm{~h}$ with or without the combination of palmitate $(0.4 \mathrm{mM})$ and oleate $(0.2 \mathrm{mM})$.

\section{Glucose uptake}

Glucose uptake was measured in triplicate, as described $(14,16)$. In brief, myotubes pretreated with or without fatty acids were stimulated with or without $100 \mathrm{nM}$ insulin (Actrapid, Novo Nordisk) for $1 \mathrm{~h}$ at $+37^{\circ} \mathrm{C}$ in the pre-treatment medium, washed from glucose and This work is licensed under a Creative Commons
Attribution-NonCommercial-NoDerivatives 4.0 International License. 
other compounds followed by $15 \mathrm{~min}$ incubation in glucose-free DMEM medium containing 0.5\% fatty acidfree BSA, $10 \mu \mathrm{M} 2$ 2-DG and $\left[{ }^{3} \mathrm{H}\right]$-2-deoxy-D-glucose $(100 \mathrm{mCi} /$ $\mathrm{mmol})$. Myotubes were washed with ice-cold PBS and lysed in $0.4 \mathrm{M} \mathrm{NaOH}$ for $3 \mathrm{~h}$ on a rotating platform. Radioactivity of the cell lysate was measured in a scintillation counter.

\section{Western blot analysis}

Myotubes pretreated with or without fatty acids were stimulated with or without $100 \mathrm{nM}$ insulin for $10 \mathrm{~min}$ at $+37^{\circ} \mathrm{C}$. Total and phosphorylated proteins were detected by Western blotting in PVDF membranes with primary antibodies from Cell Signaling: p-Akt ${ }^{\text {Ser473 }}$ (\#9271), total Akt (\#9272), pAS160 Thr642 (\#4288), total AS160 (\#2447), p-GSK-3 $\beta^{\text {Ser9 }}$ (\#9336), total GSK-3 $\beta$ (\#9315), total PERK (\#3192), p-JNK ${ }^{\text {Thr183/Tyr185 }}$ (\#9251), total JNK (\#9252), total AMPK (\#2532), from Santa Cruz: p-PERK ${ }^{\text {Thr981 }}$ (\#sc-32577) and from Millipore: p-AMPK (\#07-626). Primary antibodies were detected with horseradish peroxidase-conjugated secondary antibody, visualized by enchanced chemiluminescence (Pierce ECL 2 Western Blotting Substrate, Thermo Scientific) and quantified using ImageJ software (NIH, http://rsbweb.nih.gov/ij/).

\section{Measurement of mitochondrial ROS production}

Mitochondrial ROS levels were measured using fluorescent dye MitoSOX (Molecular Probes, Invitrogen). Cells were incubated with dye at $+37^{\circ} \mathrm{C}$ in pre-treatment medium. After $45 \mathrm{~min}$, cells were washed from the dye, trypsinized and resuspended in normal Tyrode's solution $(140 \mathrm{mM}$ $\mathrm{NaCl}, 5 \mathrm{mM} \mathrm{KCl}, 1.5 \mathrm{mM} \mathrm{CaCl}, 1 \mathrm{mM} \mathrm{MgCl}_{2}, 10 \mathrm{mM}$ HEPES, $5 \mathrm{mM}$ D-glucose, $\mathrm{pH}$ 7.4) for measurement of fluorescent intensity in a BD Accuri C6 (BD Biosciences, San Jose, CA, USA). The dye was excited at $488 \mathrm{~nm}$, and fluorescent emission was collected through FL3 channel.

\section{Reagents}

Trypsin, FBS, penicillin/streptomycin, low-glucose DMEM, L-glutamine, palmitic acid, oleic acid, Tempol, 2-DG, L-carnitine and sodium pyruvate were from Sigma. DMEM-F12, glucose-free DMEM, MitoTempo and fungizone were from Gibco. $\left[{ }^{3} \mathrm{H}\right]$-2-deoxy-D-glucose was from PerkinElmer. CD56-coupled magnetic beads were from Miltenyi Biotec (Gologna, Germany), and Actrapid insulin was from Novo Nordisk.
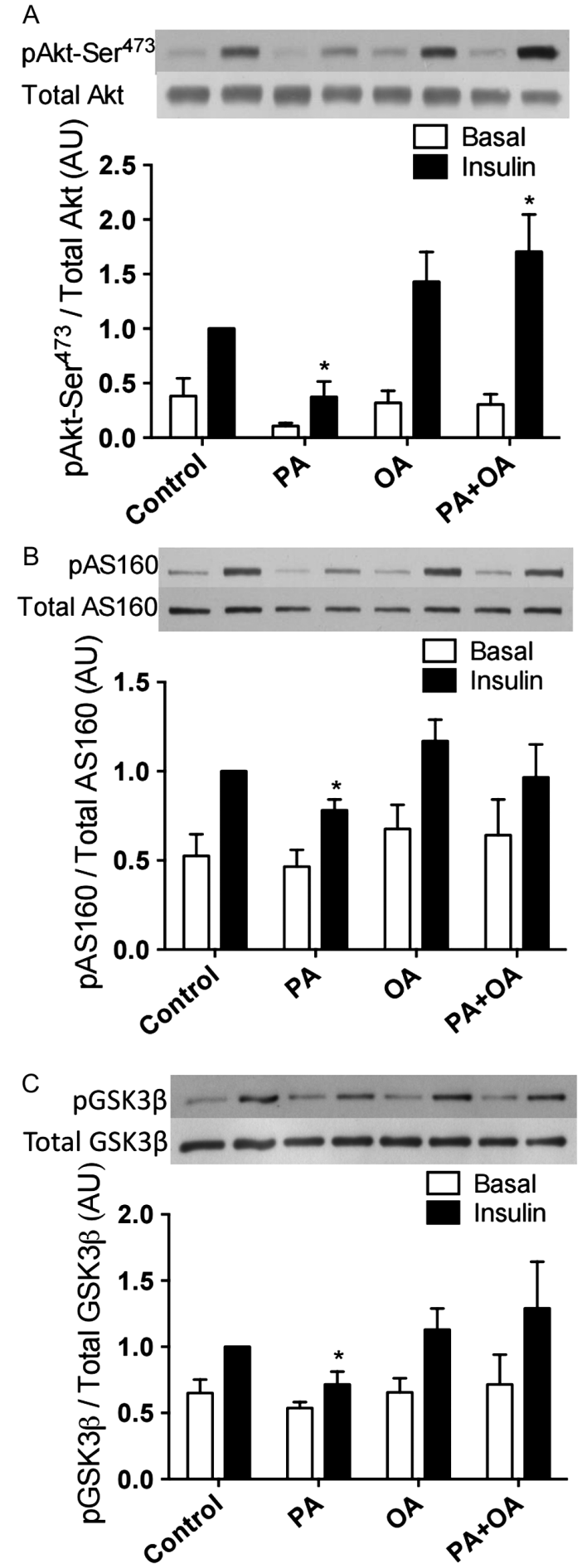

Figure 1

Phosphorylation of Akt-Ser ${ }^{473}$, AS160 and GSK-3 $\beta$. Human primary myotubes were incubated with $0.4 \mathrm{mM}$ palmitate (PA), $0.2 \mathrm{mM}$ oleate $(\mathrm{OA})$ or their combination $(\mathrm{PA}+\mathrm{OA})$, for $12 \mathrm{~h}$, and stimulated with $100 \mathrm{nM}$ insulin for $10 \mathrm{~min}$. Phosphorylation of Akt-Ser ${ }^{473}$ (A), AS160 (B) and GSK-3 $\beta$ (C) was assessed. Data are expressed as mean \pm s.E.M. from 5 men. ${ }^{*} P<0.05$ compared to insulin-stimulated control, two-way ANOVA with repeated measurements, Sidak's post hoc test (A and B), Student's paired $t$-test (C). AU, arbitrary units. 


\section{Statistical analysis}

Data are presented as mean \pm S.E.M. Statistical analyses were performed using GraphPad Prism statistical software (version 6). One- or two-way ANOVA with repeated measurements followed by Sidak's post hoc test for multiple comparisons or paired Student's $t$-test was used. $P$ value $\leq 0.05$ was considered statistically significant.

\section{Results}

\section{Insulin signalling}

Akt-Ser ${ }^{473}$ Primary human myotubes were incubated with palmitate, oleate or their combination for $12 \mathrm{~h}$. Palmitate caused a profound reduction in insulin action on Akt-Ser ${ }^{473}$ signalling, whereas oleate did not have an effect. Co-incubation with palmitate and oleate completely restored and even enhanced insulin action on Akt-Ser ${ }^{473}$ phosphorylation (Fig. 1A).

AS160 Incubation with palmitate inhibited insulinstimulated AS160 phosphorylation, and this was rescued by co-incubation with oleate (Fig. 1B).

GSK-3 $\beta$ Palmitate led to a decrease in insulin-stimulated GSK3 $\beta$ phosphorylation, which was recovered by coincubation with oleate (Fig. 1C).

\section{ER stress and AMPK signalling}

PERK Incubation with palmitate for $12 \mathrm{~h}$ induced ER stress as observed by increased PERK phosphorylation. This was restored by co-incubation with oleate (Fig. 2A).

JNK Activation of stress kinase JNK signalling is implicated in response to ER stress (17). Palmitate increased the phosphorylation of JNK isoform of $54 \mathrm{kDa}$ in muscle cells. Co-incubation with palmitate and oleate prevented JNK activation (Fig. 2B).

AMPK Phosphorylation of AMP-activated protein kinase was increased in myotubes pretreated with palmitate and oleate for $12 \mathrm{~h}$ (Fig. 2C).

\begin{tabular}{|lr}
\hline http://www.endocrineconnections.org & ○ 2017 The authors \\
DOI: 10.1530/EC-17-0039 & Published by Bioscientifica Ltd
\end{tabular}
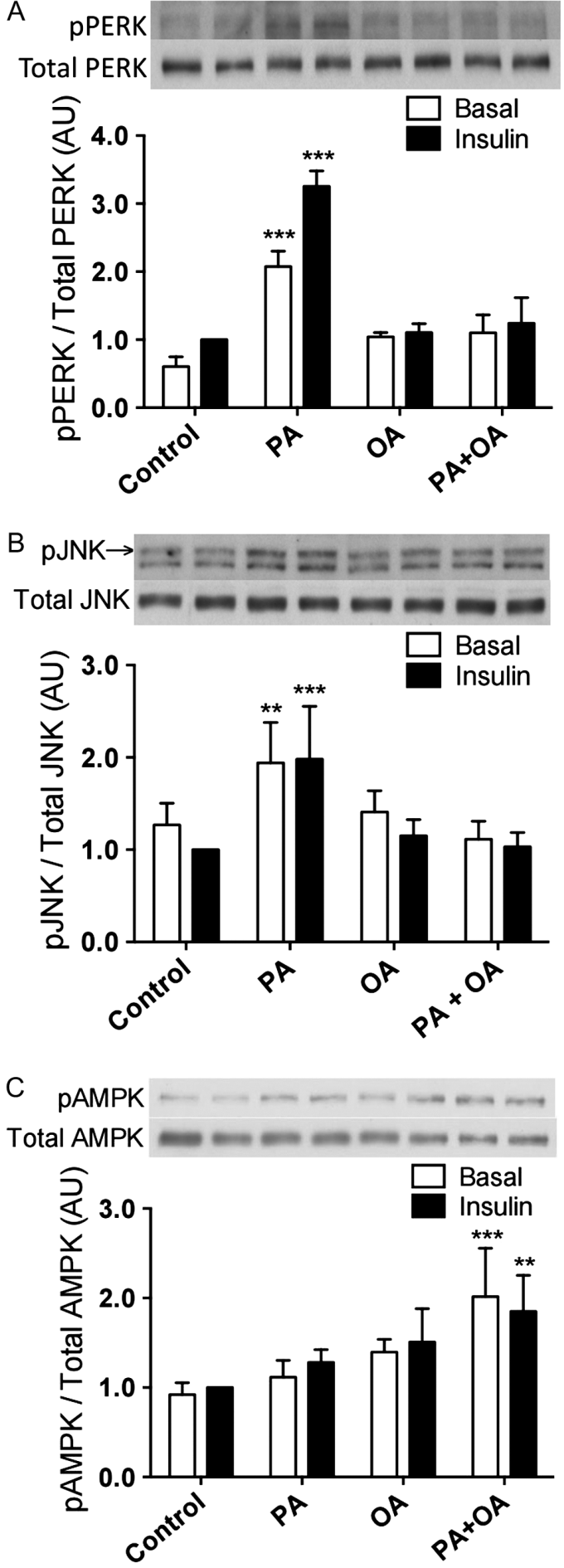

Figure 2

Phosphorylation of PERK, JNK54 and AMPK. Human primary myotubes were incubated with $0.4 \mathrm{mM}$ palmitate (PA), $0.2 \mathrm{mM}$ oleate (OA) or their combination $(P A+O A)$, for $12 \mathrm{~h}$, and stimulated with $100 \mathrm{nM}$ insulin for $10 \mathrm{~min}$. Phosphorylation of PERK (A), JNK54 (B) and AMPK (C) was assessed. Data are expressed as mean \pm S.E.M. from $4(A, B)$ and 5 (C) men. $* * P<0.01$ and $* * * P<0.001$ compared to respective control, two-way ANOVA with repeated measurements, Sidak's post hoc test. $\mathrm{AU}$, arbitrary units. 


\section{Glucose metabolism}

Glucose uptake To analyse if the observed changes in signalling events are reflected at glucose metabolism, human primary myotubes were pre-exposed to palmitate, oleate or their combination for $12 \mathrm{~h}$ before analysis of insulin-stimulated glucose uptake. Exposure to either palmitate or oleate or their combination reduced basal or insulin-stimulated glucose uptake (Fig. 3).

\section{Mitochondrial ROS production}

Since metabolism of fatty acids leads to ROS production (18), we next analysed if development of insulin resistance of glucose uptake is related to ROS. Human myotubes were exposed for $12 \mathrm{~h}$ to palmitate, oleate or their combination. Mitochondrial ROS production was significantly increased in cells incubated with both palmitate and oleate, but not with palmitate or oleate alone (Fig. 4A).

Antioxidants We next tested if insulin responsiveness in myotubes exposed to fatty acids can be restored by using antioxidants. Concomitant exposure of myotubes to mitochondrial-targeted antioxidant MitoTempo restored and even enhanced basal and insulin-stimulated glucose uptake in myotubes treated with both palmitate and oleate (Fig. 4B). Exposure to MitoTempo alone increased

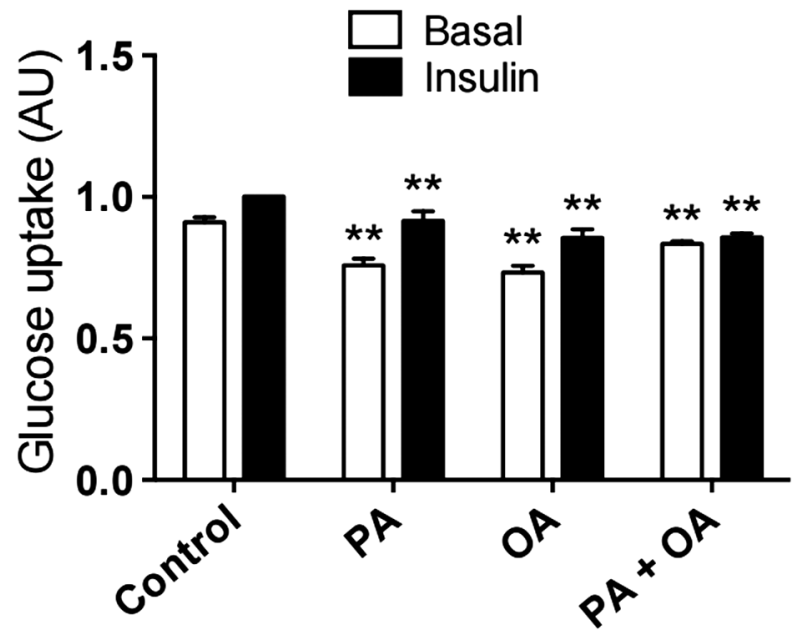

Figure 3

Glucose uptake. Human primary myotubes were pre-exposed to $0.4 \mathrm{mM}$ palmitate (PA), $0.2 \mathrm{mM}$ oleate (OA) or their combination for $12 \mathrm{~h}$ before analysis of glucose uptake with or without $100 \mathrm{nM}$ insulin. Data (in $\mathrm{pmol} / \mathrm{mg}$ protein/min) were normalized to insulin-stimulated glucose uptake (control) of each subject. Data are expressed as mean \pm S.E.M. from 5 men $* * P<0.01$ vs respective control, two-way ANOVA with repeated measurements, Sidak's post hoc test. AU, arbitrary units.
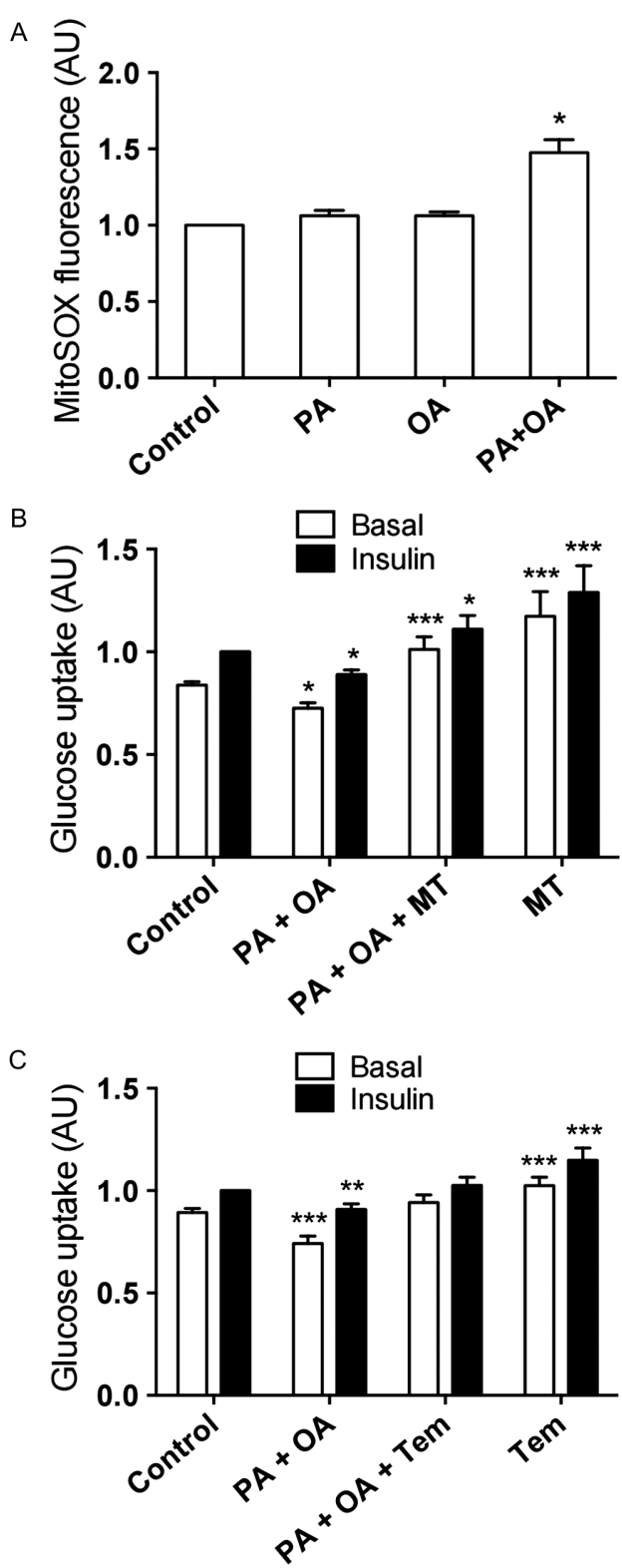

Figure 4

(A) Mitochondrial ROS. Human primary myotubes were pre-exposed to $0.4 \mathrm{mM}$ palmitate (PA), $0.2 \mathrm{mM}$ oleate (OA), or their combination for $12 \mathrm{~h}$. Mitochondrial ROS production was determined as described in the 'Materials and methods' section. Data are expressed as mean \pm s.E.M. from 5 men. ${ }^{*} P<0.05$ compared to basal, one-way ANOVA with repeated measurements, Sidak's post hoc test. (B) Glucose uptake with MitoTempo. Human primary myotubes were pre-exposed for $12 \mathrm{~h}$ to a combination of $0.4 \mathrm{mM}$ palmitate (PA) and $0.2 \mathrm{mM}$ oleate (OA), with or without $50 \mu \mathrm{M}$ MitoTempo (MT), before analysis of glucose uptake with or without $100 \mathrm{nM}$ insulin. Data are expressed as mean \pm S.E.M. from 6 men $* P<0.05$ and $* * * P<0.001$ vs respective control, two-way ANOVA with repeated measurements, Sidak's post hoc test. (C) Glucose uptake with Tempol. Human primary myotubes were pre-exposed for $12 \mathrm{~h}$ to a combination of $0.4 \mathrm{mM}$ palmitate $(\mathrm{PA})$ and $0.2 \mathrm{mM}$ oleate $(\mathrm{OA})$, with or without $0.5 \mathrm{mM}$ Tempol (Tem), before analysis of glucose uptake with or without $100 \mathrm{nM}$ insulin. Data are expressed as mean \pm S.E.M. from 6 men $* * P<0.01$ and $* * * P<0.001$ vs respective control, two-way ANOVA with repeated measurements, Sidak's post hoc test. 
basal and insulin-stimulated glucose uptake. Tempol, a small molecule cell-permeable SOD mimetic, also restored basal and insulin-stimulated glucose uptake in myotubes treated with fatty acids, and enhanced basal and insulinstimulated glucose uptake in untreated cells (Fig. 4C).

\section{Discussion}

Here, we show that exposure of primary human myotubes from healthy donors to saturated fatty acid palmitate impairs insulin signalling, increases ER stress and activates stress kinase JNK signalling. Co-incubation of primary human myotubes with monounsaturated fatty acid oleate has a protective effect by restoring defects at insulin signalling, and preventing activation of ER stress and JNK. However, the changes at the level of signalling are not translated into metabolic events, since provision of myotubes with both palmitate and oleate results in impairment of insulin action on glucose uptake. This is related to increased mitochondrial ROS production, and can be ameliorated with antioxidants.

The strength of our study is that we used carefully controlled conditions to study effects of saturated fatty acid palmitate and unsaturated fatty acid oleate in myotubes from clinically well-characterized healthy donors. The weaknesses of our study are that we only studied men and the sample size was limited. Moreover, we used only one concentration of palmitate $(0.4 \mathrm{mM})$ and oleate $(0.2 \mathrm{mM})$. However, we performed an initial doseresponse and time-course experiment using palmitate at different concentrations $(0.1,0.2$ and $0.4 \mathrm{mM})$ for a duration of 4,8 or $12 \mathrm{~h}$, and we observed a time- and dosedependent inhibition of insulin-stimulated Akt-Ser ${ }^{473}$ phosphorylation, with the maximum inhibition at $12 \mathrm{~h}$ by $0.4 \mathrm{mM}$ palmitate (data not shown here). Therefore, we chose to expose the cells to $0.4 \mathrm{mM}$ palmitate for $12 \mathrm{~h}$ in the subsequent experiments. Oleate concentration was chosen based on the study by Peng and coworkers where the negative effects of $0.5 \mathrm{mM}$ palmitate could be combated by concomitant exposure to lower $(0.1-0.2 \mathrm{mM}$ or $0.3 \mathrm{mM}$ ) oleate concentrations (12). In the future, it would be important to compare the effects of different fatty acid concentrations, and the effects of different fatty acids with varying chain lengths and degrees of saturation, on metabolism in human skeletal muscle. It would also be interesting to compare the effects of exposing muscles to different proportions of unsaturated to saturated fats.
However, our observations on the effects of different fatty acids were robust. Interestingly, several in vivo studies have provided compelling evidence that substituting saturated fat for mono- and polyunsaturated fatty acids improves metabolic health and protects against coronary artery disease $(7,8,9,10,19)$. In contrast, diet enriched in saturated fatty acids, a typical Western diet, aggravates insulin resistance $(6,7,20)$. These data suggest that different fatty acids are indeed not alike, which was also apparent in our study where the effects of palmitate and oleate on intracellular signalling in human myotubes diverged. It is possible that differential routing of fatty acids contributes to variable impact of fatty acids. Clinically, this is evident, for example, in an overfeeding experiment, where overconsumption of saturated fatty acids leads to more increased hepatic and visceral fat storage than overconsumption of polyunsaturated fatty acids, despite similar weight gain (21). Moreover, an isocaloric diet rich in polyunsaturated fatty acids diminishes hepatic fat content and may improve insulin resistance in viscerally obese people (22).

Our data on human myotubes are also in agreement with other in vitro studies. The beneficial effect of adding monounsaturated oleate to cells exposed to saturated fatty acid palmitate has been convincingly demonstrated $(11,12,13,23,24,25,26)$. Several mechanisms seem to be operative. In agreement to our observations, palmitate reduces insulin-stimulated phosphorylation of Akt. This is rescued by concomitant exposure to oleate $(12,25)$, an effect suggested to involve inhibition of protein phosphatase $2 \mathrm{~A}$ (13). Palmitate activates diacylglycerol/PKC- $\theta / \mathrm{NF}-\kappa \mathrm{B}$ pathway in mouse $\mathrm{C} 2 \mathrm{C} 12$ myotubes, which results in increased interleukin-6 secretion and downregulation of PGC- $1 \alpha$ and DGAT2. Co-incubation with oleate prevents these negative sequelae, which is suggested to be mediated by enhanced mitochondrial $\beta$-oxidation and by channelling palmitate into triglycerides (11). In another experiment, palmitate inhibited insulin signalling and increased mitochondrial ROS production. Addition of oleate to palmitate restored insulin signalling, increased ATP levels and cell viability (25). Similarly, palmitoleate, a monounsaturated fatty acid, protected from the negative effects of palmitate on glucose uptake (27).

ER stress has been suggested to play a role in the pathogenesis of insulin resistance (28). Here, we observed an activation of ER stress signalling, as reflected by increased PERK. This was associated with the activation of stress kinase JNK. Protein kinase JNK is activated via IRE1 of the unfolded protein response (UPR) signalling http://www.endocrineconnections.org DOI: 10.1530/EC-17-0039
() 2017 The authors Published by Bioscientifica Ltd
This work is licensed under a Creative Commons Attribution-NonCommercial-NoDerivatives 4.0 International License. 
pathway (17), and it phosphorylates IRS at inhibitory serine residues and thus contributes to insulin resistance by blocking PI3K pathway $(29,30)$. We demonstrate that co-incubation with oleate protects human myotubes from palmitate-induced activation of ER stress and JNK. This is in agreement with a study by Peng and coworkers where co-incubation of L6 and C2C12 muscle cells with palmitate and oleate protected cells from ER stress (12). These observations have also been confirmed by others. Studies using mouse $\mathrm{C} 2 \mathrm{C} 12$ myotubes and human myogenic cell line LHCN-M2 have revealed that co-incubation with oleate prevents palmitate-induced increase in ER stress markers (31). One possible mechanism relates to partitioning of intracellular lipids, as oleate directs palmitate into triglyceride pool. This reduces cellular active lipid metabolites such as phospholipids, DAG or ceramide $(11,12,23)$. Palmitate-induced activation of ER stress markers is also prevented by AICAR and A-769662, compounds both of which activate AMPK. Expression of dominant-negative AMPK or AMPK inhibitor compound $\mathrm{C}$ prevents the beneficial effects of oleate on palmitateinduced ER stress, inflammation and insulin resistance (31). These data suggest that the protective effects of oleate may be mediated via AMPK activation. In agreement, we observed increased AMPK phosphorylation in myotubes co-incubated with palmitate and oleate, although this was not within the scope of our study.

ROS are formed in mitochondria during aerobic metabolism. Oxidative stress is present in many physiological as well as pathophysiological states such as exercise and insulin resistance $(32,33)$. Chronic hyperinsulinemia and exposure to cytokine $\mathrm{TNF} \alpha$, dexamethasone or palmitate induce insulin resistance in 3T3-L1 adipocytes and in L6 myotubes. Each of these insults increases mitochondrial superoxide production, and insulin resistance can be reversed using interventions such as mitochondrial antioxidants or MnSOD expression. Thus, mitochondrial superoxide production is a common denominator in multiple insults that contribute to insulin resistance (33). Exposure of skeletal muscle mitochondria to even low concentrations of fatty acids results in enhanced ROS production (18). High-fat diet increases $\mathrm{H}_{2} \mathrm{O}_{2}$ emitting potential of muscle mitochondria and leads to changes in redox balance and redox buffering capacity. Moreover, insulin resistance following a diet with highfat content can be overcome by mitochondrial-targeted antioxidant or overexpression of mitochondrial-targeted catalase which catalyzes conversion of $\mathrm{H}_{2} \mathrm{O}_{2}$ to $\mathrm{H}_{2} \mathrm{O}$ (34). Overall, our data are in agreement with these observations.
When we exposed primary human myotubes to fatty acids, insulin action on glucose uptake was reduced, and an exposure to a combination of palmitate and oleate increased mitochondrial ROS production. When we treated the fatty acid-exposed cells with antioxidants, there was an amelioration of insulin resistance. These data support the concept that energy excess leads to enhanced mitochondrial ROS production and insulin resistance.

In conclusion, while monounsaturated fatty acid oleate protected human muscle cells from palmitateinduced alterations in intracellular signalling, this did not result in protection against insulin resistance - insulin action on glucose uptake remained impaired. Overall, our data fit with the emerging concept that in a situation when energy is provided in excess of energy need, cells respond with development of insulin resistance (35). Therefore, calorie restriction and energy expenditure-increasing interventions, such as exercise, remain the cornerstones of treatment of people with insulin resistance.

Declaration of interest

The authors declare that there is no conflict of interest that could be perceived as prejudicing the impartiality of the research reported.

\section{Funding}

This study has been supported by grants to HAK from Academy of Finland (grant no. 258753), Finska Läkaresällskapet, Liv och Hälsa Foundation, Sigrid Juselius Foundation and the governmental subsidy for research of Helsinki University Central Hospital (VaTR-funding). S M is supported by Doctoral School of Health Sciences (Doctoral Programme in Clinical Research) of University of Helsinki.

\section{Author contribution statement}

S M, Y H N and H A K designed the study; S M, Y H N, P S and H A K acquired the data. S M, Y H N and $\mathrm{H} \mathrm{AK}$ analysed and interpreted the data. $\mathrm{S} \mathrm{M}$ and $\mathrm{H} \mathrm{A} \mathrm{K}$ drafted the article, which was critically revised by $\mathrm{Y} \mathrm{H} \mathrm{N}$ and PS. All authors have approved the manuscript.

\section{Acknowledgements}

The authors thank all the volunteers who participated in the study.

\section{References}

1 DeFronzo RA, Jacot E, Jequier E, Maeder E, Wahren J \& Felber JP. The effect of insulin on the disposal of intravenous glucose. Results from indirect calorimetry and hepatic and femoral venous catheterization. Diabetes 198130 1000-1007. (doi:10.2337/diab.30.12.1000)

2 DeFronzo RA, Gunnarsson R, Bjorkman O, Olsson M \& Wahren J. Effects of insulin on peripheral and splanchnic glucose metabolism in noninsulin-dependent (type II) diabetes mellitus. Journal of Clinical Investigation 198576 149-155. (doi:10.1172/JCI111938)

3 Bandyopadhyay GK, Yu JG, Ofrecio J \& Olefsky JM. Increased malonyl-CoA levels in muscle from obese and type 2 diabetic subjects http://www.endocrineconnections.org DOI: 10.1530/EC-17-0039
(๔) 2017 The authors Published by Bioscientifica Ltd
This work is licensed under a Creative Commons Attribution-NonCommercial-NoDerivatives 4.0 International License. 
lead to decreased fatty acid oxidation and increased lipogenesis; thiazolidinedione treatment reverses these defects. Diabetes $2006 \mathbf{5 5}$ 2277-2285. (doi:10.2337/db06-0062)

4 Kraegen EW \& Cooney GJ. Free fatty acids and skeletal muscle insulin resistance. Current Opinion in Lipidology 200819 235-241. (doi:10.1097/01.mol.0000319118.44995.9a)

5 Koves TR, Ussher JR, Noland RC, Slentz D, Mosedale M, Ilkayeva O, Bain J, Stevens R, Dyck JRB, Newgard CB, et al. Mitochondrial overload and incomplete fatty acid oxidation contribute to skeletal muscle insulin resistance. Cell Metabolism 20087 45-56. (doi:10.1016/j.cmet.2007.10.013)

$6 \mathrm{Hu}$ FB, van Dam RM \& Liu S. Diet and risk of Type II diabetes: the role of types of fat and carbohydrate. Diabetologia $2001 \mathbf{4 4} 805-817$. (doi:10.1007/s001250100547)

7 Vessby B, Uusitupa M, Hermansen K, Riccardi G, Rivellese AA, Tapsell LC, Nälsén C, Berglund L, Louheranta A, Rasmussen $\mathrm{BM}$, et al. Substituting dietary saturated for monounsaturated fat impairs insulin sensitivity in healthy men and women: the KANWU Study. Diabetologia 200144 312-319. (doi:10.1007/ s001250051620)

8 Parillo M, Rivellese AA, Ciardullo AV, Capaldo B, Giacco A, Genovese S \& Riccardi G. A high-monounsaturated-fat/low-carbohydrate diet improves peripheral insulin sensitivity in non-insulin-dependent diabetic patients. Metabolism 199241 1373-1378. (doi:10.1016/00260495(92)90111-M)

9 Estruch R, Ros E, Salas-Salvadó J, Covas M-I, Corella D, Arós F, Gómez-Gracia E, Ruiz-Gutiérrez V, Fiol M, Lapetra J, et al. Primary prevention of cardiovascular disease with a Mediterranean diet. New England Journal of Medicine 2013368 1279-1290. (doi:10.1056/ NEJMoa1200303)

10 Salas-Salvadó J, Bulló M, Estruch R, Ros E, Covas M-I, IbarrolaJurado N, Corella D, Arós F, Gómez-Gracia E, Ruiz-Gutiérrez V, et al. Prevention of diabetes with Mediterranean diets: a subgroup analysis of a randomized trial. Annals of Internal Medicine 2014160 1-10. (doi:10.7326/m13-1725)

11 Coll T, Eyre E, Rodríguez-Calvo R, Palomer X, Sánchez RM, Merlos M, Laguna JC \& Vázquez-Carrera M. Oleate reverses palmitate-induced insulin resistance and inflammation in skeletal muscle cells. Journal of Biological Chemistry 2008283 11107-11116. (doi:10.1074/jbc. M708700200)

12 Peng G, Li L, Liu Y, Pu J, Zhang S, Yu J, Zhao J \& Liu P. Oleate blocks palmitate-induced abnormal lipid distribution, endoplasmic reticulum expansion and stress, and insulin resistance in skeletal muscle. Endocrinology 2011152 2206-2218. (doi:10.1210/ en.2010-1369)

13 Nardi F, Lipina C, Magill D, Hage Hassan R, Hajduch E, Gray A \& Hundal HS. Enhanced insulin sensitivity associated with provision of mono and polyunsaturated fatty acids in skeletal muscle cells involves counter modulation of PP2A. PLOS ONE 20149 e92255. (doi:10.1371/ journal.pone.0092255)

14 Skrobuk P, Kraemer S, Semenova MM, Zitting A \& Koistinen HA. Acute exposure to resveratrol inhibits AMPK activity in human skeletal muscle cells. Diabetologia 201255 3051-3060. (doi:10.1007/ s00125-012-2691-1)

15 Cousin SP, Hügl SR, Wrede CE, Kajio H, Martin G, Myers J \& Rhodes CJ. Free fatty acid-induced inhibition of glucose and insulin-like growth factor I-induced deoxyribonucleic acid synthesis in the pancreatic $\beta$-cell line INS-1. Endocrinology 2001142 229-240. (doi:10.1210/endo.142.1.7863)

16 Al-Khalili L, Chibalin AV, Kannisto K, Zhang BB, Permert J, Holman GD, Ehrenborg E, Ding VD, Zierath JR \& Krook A. Insulin action in cultured human skeletal muscle cells during differentiation: assessment of cell surface GLUT4 and GLUT1 content. Cellular and Molecular Life Sciences 200360 991-998. (doi:10.1007/ s00018-003-3001-3)
17 Urano F, Wang X, Bertolotti A, Zhang Y, Chung P, Harding HP \& Ron D. Coupling of stress in the ER to activation of JNK protein kinases by transmembrane protein kinase IRE1. Science 2000287 664-666. (doi:10.1126/science.287.5453.664)

18 Seifert EL, Estey C, Xuan JY \& Harper M-E. Electron transport chaindependent and -independent mechanisms of mitochondrial $\mathrm{H} 2 \mathrm{O} 2$ emission during long-chain fatty acid oxidation. Journal of Biological Chemistry 2010285 5748-5758. (doi:10.1074/jbc.M109.026203)

19 Kien CL, Bunn JY, Poynter ME, Stevens R, Bain J, Ikayeva O, Fukagawa NK, Champagne CM, Crain KI, Koves TR, et al. A lipidomics analysis of the relationship between dietary fatty acid composition and insulin sensitivity in young adults. Diabetes 201362 1054-1063. (doi:10.2337/db12-0363)

20 Maron DJ, Fair JM \& Haskell WL. Saturated fat intake and insulin resistance in men with coronary artery disease. The Stanford Coronary Risk Intervention Project Investigators and Staff. Circulation 199184 2020-2027. (doi:10.1161/01.CIR.84.5.2020)

21 Rosqvist F, Iggman D, Kullberg J, Cedernaes J, Johansson H-E, Larsson A, Johansson L, Ahlström H, Arner P, Dahlman I, et al. Overfeeding polyunsaturated and saturated fat causes distinct effects on liver and visceral fat accumulation in humans. Diabetes 201463 2356-2368. (doi:10.2337/db13-1622)

22 Bjermo H, Iggman D, Kullberg J, Dahlman I, Johansson L, Persson L, Berglund J, Pulkki K, Basu S, Uusitupa M, et al. Effects of n-6 PUFAs compared with SFAs on liver fat, lipoproteins, and inflammation in abdominal obesity: a randomized controlled trial. American Journal of Clinical Nutrition 201295 1003-1012. (doi:10.3945/ ajcn.111.030114)

23 Listenberger LL, Han X, Lewis SE, Cases S, Farese RV, Ory DS \& Schaffer JE. Triglyceride accumulation protects against fatty acidinduced lipotoxicity. PNAS 2003100 3077-3082. (doi:10.1073/ pnas.0630588100)

24 Gao D, Griffiths HR \& Bailey CJ. Oleate protects against palmitateinduced insulin resistance in L6 myotubes. British Journal of Nutrition 2009102 1557-1563. (doi:10.1017/S0007114509990948)

25 Yuzefovych L, Wilson G \& Rachek L. Different effects of oleate vs. palmitate on mitochondrial function, apoptosis, and insulin signaling in L6 skeletal muscle cells: role of oxidative stress. American Journal of Physiology: Endocrinology and Metabolism 2010299 E1096-E1105. (doi:10.1152/ajpendo.00238.2010)

26 Kwon B, Lee H-K \& Querfurth HW. Oleate prevents palmitate-induced mitochondrial dysfunction, insulin resistance and inflammatory signaling in neuronal cells. Biochimica et Biophysica Acta (BBA): Molecular Cell Research 20141843 1402-1413. (doi:10.1016/j. bbamcr.2014.04.004)

27 Dimopoulos N, Watson M, Sakamoto K \& Hundal HS. Differential effects of palmitate and palmitoleate on insulin action and glucose utilization in rat L6 skeletal muscle cells. Biochemical Journal 2006399 473-481. (doi:10.1042/BJ20060244)

28 Ozcan U, Cao Q, Yilmaz E, Lee A-H, Iwakoshi NN, Ozdelen E, Tuncman G, Gorgun C, Glimcher LH \& Hotamisligil GS. Endoplasmic reticulum stress links obesity, insulin action, and type 2 diabetes. Science 2004306 457-461. (doi:10.1126/science.1103160)

29 Aguirre V, Uchida T, Yenush L, Davis R \& White MF. The c-Jun NH2-terminal kinase promotes insulin resistance during association with insulin receptor substrate-1 and phosphorylation of Ser307. Journal of Biological Chemistry 2000275 9047-9054. (doi:10.1074/ jbc.275.12.9047)

30 Hirosumi J, Tuncman G, Chang L, Gorgun CZ, Uysal KT, Maeda K, Karin M \& Hotamisligil GS. A central role for JNK in obesity and insulin resistance. Nature 2002420 333-336. (doi:10.1038/ nature01137)

31 Salvadó L, Coll T, Gómez-Foix AM, Salmerón E, Barroso E, Palomer X \& Vázquez-Carrera M. Oleate prevents saturated-fatty-acid-induced ER stress, inflammation and insulin resistance in skeletal muscle

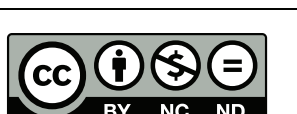

This work is licensed under a Creative Commons Attribution-NonCommercial-NoDerivatives 4.0 International License. 
cells through an AMPK-dependent mechanism. Diabetologia 201356 1372-1382. (doi:10.1007/s00125-013-2867-3)

32 Powers SK \& Jackson MJ. Exercise-induced oxidative stress: cellular mechanisms and impact on muscle force production. Physiological Reviews 200888 1243-1276. (doi:10.1152/physrev.00031.2007)

33 Hoehn KL, Salmon AB, Hohnen-Behrens C, Turner N, Hoy AJ, Maghzal GJ, Stocker R, Van Remmen H, Kraegen EW, Cooney GJ, et al. Insulin resistance is a cellular antioxidant defense mechanism. PNAS 2009106 17787-17792. (doi:10.1073/pnas.0902380106)
34 Anderson EJ, Lustig ME, Boyle KE, Woodlief TL, Kane DA, Lin C-T, Price JW, Kang L, Rabinovitch PS, Szeto HH, et al. Mitochondrial $\mathrm{H} 2 \mathrm{O} 2$ emission and cellular redox state link excess fat intake to insulin resistance in both rodents and humans. Journal of Clinical Investigation 2009119 573-581. (doi:10.1172/ JCI37048)

35 Muoio DM \& Neufer PD. Lipid-induced mitochondrial stress and insulin action in muscle. Cell Metabolism 201215 595-605. (doi:10.1016/j.cmet.2012.04.010)

Received in final form 27 April 2017

Accepted 2 June 2017

Accepted Preprint published online 5 June 2017
This work is licensed under a Creative Commons Attribution-NonCommercial-NoDerivatives 4.0 International License. 